\title{
A quantitative approach for integrating multiple lines of evidence for the evaluation of environmental health risks
}

Jerome J Schleier III, Lucy A Marshall, Ryan S Davis, Robert K Peterson

Decision analysis often considers multiple lines of evidence during the decision making process. Researchers and government agencies have advocated for quantitative weightof-evidence approaches in which multiple lines of evidence can be considered when estimating risk. Therefore, we utilized Bayesian Markov Chain Monte Carlo to integrate several human-health risk assessments, biomonitoring, and epidemiology studies that have been conducted for two common insecticides (malathion and permethrin) used for adult mosquito management to generate an overall estimate of risk quotient (RQ). The utility of the Bayesian inference for risk management is that the estimated risk represents a probability distribution from which the probability of exceeding a threshold can be estimated. The mean RQs after all studies were incorporated were 0.4386 with a variance of 0.0163 for malathion and 0.3281 with a variance of 0.0083 for permethrin. After taking into account all of the evidence available on the risks of ULV insecticides, the probability that malathion or permethrin would exceed a level of concern was less than 0.0001 . Bayesian estimates can substantially improve decisions by allowing decision makers to estimate the probability that a risk will exceed a level of concern by considering seemingly disparate lines of evidence. 
2 Jerome J. Schleier III, Lucy A. Marshall, Ryan S. Davis, and Robert K. D. Peterson*

3 Department of Land Resources and Environmental Sciences, Montana State University, 334 Leon 4 Johnson Hall, Bozeman, MT 59717, USA

5 *Corresponding author, Robert K. D. Peterson. Department of Land Resources and

6 Environmental Sciences, Montana State University, Bozeman, Montana, 59717-3120, 406-994-

7 7927; bpeterson@montana.edu. 


\section{Introduction}

Modeling and decision theory are being used increasingly for comparative and uncertainty analysis in risk management (Ascough et al. 2008). Researchers have advocated for a quantitative weight-of-evidence approach for estimating environmental risks from stressors such as contaminated sites and pesticides so that decision makers can comprehensively consider all

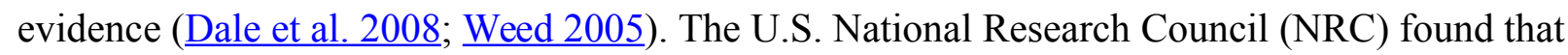
the U.S. Environmental Protection Agency (USEPA) needs to develop methods to address and communicate uncertainty and variability in all phases of the risk assessment process ( $\underline{\text { NRC 2009). }}$. The NRC stated that "Uncertainty forces decision makers to judge how probable it is that risks will be overestimated or underestimated for every member of the exposed population..." (NRC 1994). In particular, the NRC reports found that depending on the risk-management options, a quantitative treatment of uncertainty and variability is needed to discriminate between

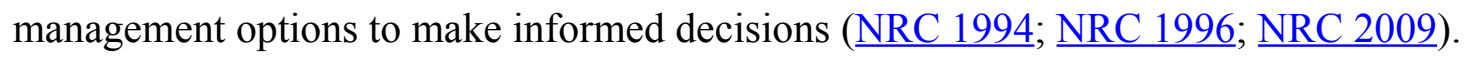

When making decisions regarding risk, there are often multiple lines of evidence that need to be considered. Information often is generated and gathered from different sources, so risk analysts and managers are confronted with the issue of combining data from these sources to improve the decision-making process. However, the ability of people to make precise and significant statements about risks diminishes with increasing amounts of information and complexity (Zadeh 1965). The incorporation of multiple lines of evidence into a weight-ofevidence framework allows risk assessors and managers to generate a single estimate of the risk (Dale et al. 2008). Currently, the most common way to incorporate dissimilar lines of evidence is by determining the weight-of-evidence estimate through qualitative risk assessments or through listing evidence (Chapman et al. 2002; Hull \& Swanson 2006; Linkov et al. 2009; $\underline{\text { Menzie et al. }}$ 1996; Sanchez-Bayo et al. 2002; Suter II \& Cormier 2011; USEPA 2005a; Weed 2005), which can have fundamental mathematical limitations compared to quantitative estimates ( $\underline{\text { Cox Jr. et al. }}$. 
$33 \underline{2005}$ ). These methods are important contributions to the decision making process, but they do not

34 provide a comprehensive and structured approach for integrating multiple lines of evidence from

35 different study types (Linkov et al. 2009).

36 Rather than testing for a specific relationship (e.g., the probability of obtaining values as

37 extreme or more extreme than the values observed in the study), decision makers may ultimately

38 be interested in making inferential conclusions about environmental health risks (Assmuth \&

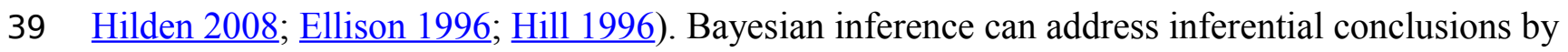

40 providing a framework, based on probability calculus, by quantifying the uncertainty in

41 parameter estimates and determining the probability that an explicit endpoint is exceeded given a

42 set of data (Ellison 1996; Hill 1996). Bayesian inference is a way of updating prior knowledge

43 given new information becoming available to generate a posterior estimate of the parameters of

44 interest (i.e., risk) (Ellison 1996).

45 Currently there are few quantitative frameworks that integrate data into a framework that

46 can be utilized by risk managers (Assmuth \& Hilden 2008). A quantitative framework for

47 integrating and interpreting multiple lines of seemingly disparate evidence into an overall risk

48 estimate is critically needed for complex risk assessments (Dale et al. 2008).

49 Risk assessments, biomonitoring, and epidemiology studies quantitatively estimate the

50 likelihood that exposures to chemicals of interest exceed a threshold of observable effect or

51 increased exposure over background levels in a population (McKone et al. 2009).

52 Epidemiological and biomonitoring data can play an important role in hazard identification and

53 can also be considered in the risk characterization phase of the risk assessment process (

54 al. 1998). Therefore, the three seemingly disparate study methods are deriving an estimate of risk

55 given exposure to the chemical of interest. Bayesian inference provides a quantitative framework

56 for integrating these multiple lines of evidence into an overall estimate. Similar approaches have

57 been used for different applications in risk assessment, toxicology, and environmental modeling, 
58 but they have not been utilized to update the risk estimates for anthropogenic chemical stressors

59 as new information becomes available (Bernillon \& Bois 2000; Brand \& Small 1995; Devine \&

60 Qualters 2008; Schenker et al. 2009; Taylor et al. 1993).

61 There are many advantages of using Bayesian techniques for weighing evidence,

62 including full allowance for all parameter uncertainty in the model, the ability to include other

63 pertinent information that would otherwise be excluded, and the ability to extend the models to

64 accommodate more complex models ( $\underline{\text { Hill 1996; }}$ Sutton \& Abrams 2001). Studies utilizing

65 Bayesian approaches have considered separate studies with the same study type to estimate an

66 overall value for the parameter of interest (Smith et al. 2002; Wheeler \& Bailer 2009). Therefore,

67 to address the need for a quantitative approach for environmental health, we utilized Bayesian

68 Markov chain Monte Carlo to provide a logical and consistent method for estimating the risk of

69 chemicals when multiple studies are available. To demonstrate how Bayesian statistics can be

70 used for decisions regarding environmental and public health risks, we chose insecticides used

71 for adult mosquito management as our case study.

\section{Case Study}

73 To effectively manage infection rates, morbidity, and mortality due to mosquito-borne

74 pathogens, there must be a reduction in contact between infected mosquitoes and humans and

75 animals (Marfin \& Gubler 2001). One of the more effective ways of managing high densities of

76 adult mosquitoes that vector human and animal pathogens is ultra-low-volume (ULV) aerosol

77 applications of insecticides. Since West Nile virus (WNV) was introduced into the U.S., more

78 areas of the country have been experiencing large-scale insecticide applications. Consequently,

79 there has been greater public attention on human-health and environmental risks associated with

80 ULV insecticide applications (Peterson et al. 2006; Reisen \& Brault 2007; Roche 2002; Thier

81 2001). 
82 A decade after the initial response to $\mathrm{WNV}$, several quantitative human-health and

83 ecological risk assessments have been conducted to estimate the magnitude of risks associated

84 with the insecticides (Davis 2007; Davis et al. 2007; Gosselin et al. 2008; Macedo et al. 2007;

85 NYCDOH 2005; Peterson et al. 2006; Schleier III 2008; Schleier III et al. 2009a; Schleier III et

86 al. 2008a; Schleier III et al. 2009b; Schleier III et al. 2008b; Suffolk County 2006; USEPA

87 2005b; USEPA 2005c; USEPA 2005d; USEPA 2006a; USEPA 2006b; USEPA 2006c; Valcke et

88 al. 2008). Also, there have been epidemiology and biomonitoring studies measuring the health

89 effects after potential exposure to mosquito adulticides (Currier et al. 2005; Duprey et al. 2008;

90 Karpati et al. 2004; Kutz \& Strassman 1977; O'Sullivan et al. 2005). Most studies suggest

91 negligible public health risks from exposure to adulticides; however, no study has quantitatively

92 combined the results from risk assessment, epidemiology, and biomonitoring studies, and there

93 seemingly disparate data metrics, to obtain an overall estimate of the risk.

\section{Data and Methods}

In environmental and human health risk assessments of pesticides, risk quotients (RQ) are often used to quantitatively express risk (Peterson 2006). Risk quotients are calculated by

97 dividing the potential exposure (PE) by its respective toxic endpoint value. Estimated RQs are 98 compared to a RQ level of concern (LOC) or other threshold which is set by the USEPA or 99 another regulatory agency to determine if regulatory action is needed. The RQ LOC used in our 100 assessment was 1.0. An RQ $>1.0$ means that the estimated exposure is greater than the relevant 101 toxicological endpoint. If an RQ breaches a regulatory $\mathrm{LOC}(\mathrm{RQ} \geq 1)$ at a lower tier, then risk 102 managers decide to restrict the product use, progress to higher tier risk assessments, or use field103 verified models (USEPA 2006d).

104 We chose two pesticides for our case study, malathion (O,O-dimethyl dithiophosphate of 105 diethyl mercaptosuccinate) and permethrin ([3-phenoxyphenyl]methyl 3-[2,2-dichloroethenyl]106 2,2-dimethylcyclopropane carboxylate), because biomonitoring, epidemiology, and risk 
107 assessments have been performed with respect to ULV applications for adult mosquito

108 management (Table 1). We chose adult human males for our case study because it is the only

109 common group assessed by all studies. To ensure that we possessed all publically available

110 studies, a literature review was performed and all relevant studies were pulled from government

111 reports and academic journals from 1900 to 2014 using the Google and Thomas Reuters Web of

112 Science ${ }^{\mathrm{TM}}$ search engines. All studies that we found that contained mosquito ULV risk

113 assessments, biomonitoring, or epidemiological measurements for permethrin or malathion were

114 included in this assessment.

115 The estimated RQs for each study are summarized in Table 1 for each chemical. The same

116 toxicological endpoints were used for all of the risk assessments, which are based on the U.S.

117 EPA's ingestion reference dose for mammals (Macedo et al. 2007; Peterson et al. 2006; $\underline{\text { Schleier }}$

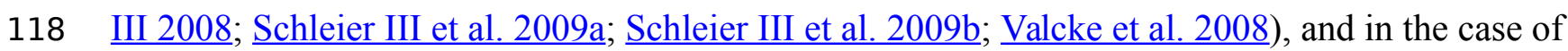

119 probabilistic risk assessments we used the $95^{\text {th }}$ percentile RQ for conservatism.

120 The literature search found two epidemiological studies and one biomonitoring study for

121 permethrin and malathion. Karpati et al. (2004) analyzed hospital admissions for asthma in New

122 York, NY three days before and after ground based ULV applications of permethrin $(n=510$

123 before spraying and 501 after spraying) and found no increase in admissions for asthma. Currier

124 et al. (2005) analyzed urine samples for metabolites of permethrin in 125 persons in the treated

125 area and 67 persons from two control areas after ground-based ULV applications in Mississippi

126 and found no increase in urinary metabolites. The persons selected in the study were

127 geographically random and were verified by mapping the GPS location of the ground-based

128 applications. O'Sullivan et al. (2005) analyzed hospital admissions for asthma in New York, NY

129 after ground-based ULV applications of malathion in September of 1999 and compared those to

130 September 1997 and 1998 which no malathion treatments occurred $(n=1318$ patients presented

131 with a diagnosis of asthma exacerbation). They found no statistical difference between the 1999 
132 asthma admissions and the asthma admission in 1997 and 1998. To incorporate the epidemiology

133 and biomonitoring studies, we assumed that if the researchers did not observe an effect or

134 increase in urinary metabolites of the pesticide, the RQ was assumed to be 0.99 (Table 1). We

135 assumed a RQ of 0.99 to be conservative because of a lack of knowledge on the value, which

136 must be below 1.0 if no effect is observed.

137 Bayesian inference treats statistical parameters as random variables, and uses a likelihood

138 function to express the plausibility of obtaining different values of the parameter when the data

139 have been observed (Ellison 1996). To define a RQ for adult males we used Bayes' theorem:

$140 \mathrm{p}(\theta \mid \mathrm{y})=\mathrm{p}(\mathrm{y} \mid \theta) \mathrm{p}(\theta)$

141 where $\mathrm{p}$ is the probability mass, $\theta$ is the value of a random variable selected from the prior

142 distribution, $y$ is the evidence being considered, $p(\theta)$ is the prior probability, $\mathrm{p}(\mathrm{y} \mid \theta)$ is the

143 likelihood function for the evidence (Congdon 2006; Gelman et al. 2004). We assumed a normal

144 distribution for the likelihood function and used log-transformed risk quotients from table 1 . The

145 central limit theorem of classical statistics and the Bayesian analog justify the normal density as

146 an approximation for the posterior distribution of many summary statistics, even when they are

147 derived from non-normal data (Congdon 2006). To estimate the posterior density,

$148 \quad \mathrm{p}(\mathrm{y} \mid \theta)=1 \div \sqrt{ } 2 \pi \sigma \exp -1 \div 2 \sigma^{2}(\mathrm{y}-\theta)^{2}$

149 where $y$ is a single scalar observation from the RQ's in table 1 from a normal distribution

150 parameterized by a mean of $\theta$ and a variance of $\sigma^{2}$ (Gelman et al. 2004).

151 We have no knowledge of the prior distribution, so we assumed an uninformative or

152 diffuse prior which we defined as a normal distribution with a $\mu_{0}$ of 1 and a $\tau^{2}$ of 1 . We chose an

153 uninformative prior because the effect of the prior and data on the updated beliefs depends on the

154 precision of the density of $\mathrm{p}(\theta)$ (Congdon 2008). We used Markov Chain Monte Carlo simulation

155 (MCMC) utilizing the Metropolis-Hasting algorithm to obtain the posterior distribution for 
156 equation 2 using Matlab ${ }^{\circledR}$ R2010b (MathWorks, Natick, MA, USA). We sampled the purposed

157 posterior distributions using equation 2 by iterating 100,000 purposed values for the posterior

158 distribution and discarded the first 1,000 samples for burn in.

159 Results and Discussion

160 The mean posterior RQs after all studies were incorporated were 0.4386 with a variance

161 of 0.0163 for malathion and 0.3281 with a variance of 0.0083 for permethrin (Figures 1 and 2).

162 The mean posterior RQs for all studies excluding the epidemiological and biomonitoring studies

163 slightly decreased the mean to 0.4119 with a variance of 0.0158 for malathion and a mean of

1640.302 with a variance of 0.0081 for permethrin (Figures 1 and 2). Using the posterior mean and

165 variance from the normal distribution, the probability that exposure to malathion or permethrin

166 after ULV applications would exceed a level of concern was less than 0.0001, regardless of

167 whether all of the studies were incorporated or the epidemiological and biomonitoring studies

168 were held out (Figures 1 and 2).

169 The risk assessments used different data and exposure scenarios to estimate the RQ. The

170 utility of the Bayesian inference for risk management is that the estimated RQ represents a

171 probability distribution from which we can obtain a probability of exceeding a threshold (Figures

1721 and 2). The probability of exceeding a threshold is most likely more intuitive for risk managers

173 and the public to understand than an estimate of the $95^{\text {th }}$ percentile of exposure or risk, which is

174 typically reported in probabilistic risk assessments (ill 1996). In fact, risk can be defined as the

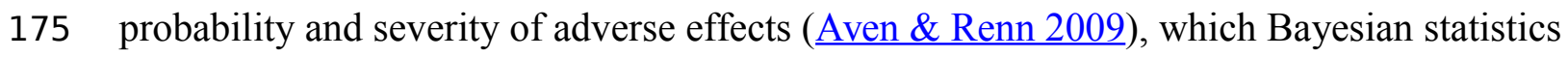

176 directly addresses. The majority of weight-of-evidence studies do not quantify both a risk

177 estimate and variability or uncertainty around that estimate, but Bayesian MCMC methods

178 quantify both (Linkov et al. 2009).

179 The USEPA provides guidance on how to perform risk assessments that address

180 variability and uncertainty (NRC 2009; USEPA 1989; USEPA 2004), but they do not provide a 
181 simple method for integrating multiple lines of evidence. Our case study directly addresses the

182 need for a standard approach by which multiple lines of evidence can be interpreted in a

183 framework that ecologists, risk assessors and managers, and NRC have highlighted (Dale et al.

184 2008; Linkov et al. 2009; NRC 1994; NRC 1996; NRC 2009). Our method also could be utilized

185 by the Network Reference Laboratories for Monitoring of Emerging Environmental Pollutants in

186 the European Union for integrating risk assessments and biomonitoring to prioritize pollutants

187 (Tilghman et al. 2009).

The USEPA and other regulatory agencies potentially could benefit from using a value-of-

189 information approach that takes advantage of Bayesian inference to determine if generating new

190 data will significantly improve the risk estimate, similar to approaches used for toxicological

191 studies (NRC 2009; Taylor et al. 1993). Our analysis showed that the addition of epidemiological

192 and biomonitoring studies using conservative estimates did not drastically change the estimate of

193 risk. Biomonitoring assessments could provide a refined RQ estimate if the amount of chemical

194 the person is exposed to is calculated. Bayesian inference can also incorporate expert knowledge

195 of a system which can be used as prior information that is updated by data (Gargoum 2001;

196 Morris 1977).

197 In ecotoxicology and other disciplines, there are multiple estimates of values like the

198 lethal concentration that kills $50 \%$ of a population (LC50) (Wheeler \& Bailer 2009). This

199 technique could be used to estimate an overall LC50 for use in risk assessments or setting total

200 maximum daily load limits. Stauffer (2008) showed that in natural resource management there

201 are often multiple estimations for a population of interest. Therefore, Bayesian MCMC methods

202 can be used to estimate the probability of the population being above or below a given threshold.

203 Bayesian analysis provides a systematic approach for guiding the decision-making

204 process by incorporating new knowledge in the estimate of risk, which directly addresses NRC

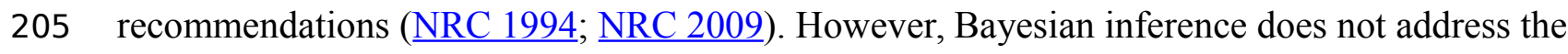


206

207

208

209

210

211

212

213

214

216

217

218

219

220

221

222

223

224

225

226

227

228

229

230

uncertainties inherent in each risk assessment. For example, there is large uncertainty

surrounding the estimate of insecticide air concentrations and deposition on surfaces after ULV

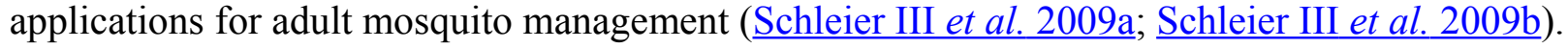

Models used by the USEPA and other researchers to estimate concentrations are either over- or under-estimating depending on the model (Schleier III \& Peterson 2010; $\underline{\text { Schleier III et al. }}$

$\underline{2008 \mathrm{~b}}$ ). In addition, probabilistic risk assessments demonstrated that the estimated air concentration and deposition of insecticides are contributing the largest amount of variance to the potential exposure (Schleier III et al. 2009a; Schleier III et al. 2009b). However, the estimate presented here most likely is robust against these uncertainties because the studies used a variety of models, exposure pathways, and monitoring techniques which were not dependent on a standardized assessment protocol.

We recognize that the assumptions about RQ distributions may affect the final results; however, we attempted to reduce the potential biases by making conservative assumptions erring on the side of safety, which is common practice in risk assessment. In addition, probability distributions other than normal can be utilized if enough is known about the underlying distribution of the population, like those used for toxicological studies. Bayesian MCMC also can be utilized with the current data and the incorporation of expert judgments to aid in the determination of risk estimates (Grist et al. 2005).

Bayesian analysis techniques have been underutilized with respect to environmental and public health, risk assessment, ecology, and environmental sciences (lark 2005). Our method is a quantitative approach to statistically derive risk estimates from multiple lines of evidence, which is a relatively simple way of integrating multiple lines of evidence into a framework that can be used by assessors and managers (Assmuth \& Hilden 2008; Linkov et al. 2009). In addition to insecticide risk, this approach can be used for other anthropogenic agents such as dioxins and polychlorinated biphenyls, which in many cases have risk assessments, biomonitoring, and 
231 epidemiology studies performed for a site. The method presented here can also be utilized for

232 probabilistic ecological risk assessments to derive a distribution for the toxicological endpoints

233 like LC50 or no-effect concentration when multiple values are available for the same species.

234 Future refinements to our Bayesian model would be the development of a method to convert

235 epidemiological study results into a RQ to reduce the uncertainty and conservatism. In addition,

236 biomonitoring studies can quantify the exposure if exposures are above background levels and 237 convert those estimates to RQ.

238 Acknowledgements

239 We thank K. Irvine (U.S. Geological Survey) for reviewing an earlier version of the 240 manuscript. 
241

242 Ascough JC, Maier HR, Ravalico JK, and Strudley MW. 2008. Future research challenges for 243

244

245

246

247

248

249

250

251

252

253

254

255

256

257

258

259

260

261

262

263

264

265

\section{References} incorporation of uncertainty in environmental and ecological decision-making. Ecological Modelling 219:383-399.

Assmuth T, and Hilden M. 2008. The significance of information frameworks in integrated risk assessment and management. Environmental Science and Policy 11:71-86.

Aven T, and Renn O. 2009. On risk defined as an event where the outcome is uncertain. Journal of Risk Research 12:1 - 11.

Bernillon P, and Bois FY. 2000. Statistical issues in toxicokinetic modeling: a Bayesian perspective. Environmental Health Perspectives 108:883-893.

Brand KP, and Small MJ. 1995. Updating uncertainty in an integrated risk assessment: conceptual framework and methods. Risk Analysis 15:719-731.

Chapman PM, McDonald BG, and Lawrence GS. 2002. Weight-of-evidence issues and frameworks for sediment quality (and other) assessments. Human and Ecological Risk Assessment 8:1489-1515.

Clark JS. 2005. Why environmental scientists are becoming Bayesians. Ecology Letters 8:2-14. Congdon P. 2006. Bayesian statistical modelling. West Sussex, England: John Wiley and Sons, Ltd.

Congdon P. 2008. Bayesian statistics in quantitative risk assessment. In: Everitt B, and Melnick E, editors. Encyclopedia of Quantitative Risk Analysis and Assessment. Hoboken, NJ: John Wiley and Sons Inc. p 119-136.

Cox Jr. LA, Babayev D, and Huber W. 2005. Some limitations of qualitative risk rating systems. Risk Analysis 25:651-662.

Currier M, McNeill M, Campbell D, Newton N, Marr JS, Perry E, Berg SW, Barr DB, Luber GE, Kieszak SM, Rogers HS, Backer SC, Belson MG, Rubin C, Azziz-Baumgartner E, and 
Duprey ZH. 2005. Human exposure to mosquito-control pesticides---Mississippi, North Carolina, and Virginia, 2002 and 2003. MMWR Morbidity and Mortality Weekly Report

269

270

271 $54: 529-532$.

Dale VH, Biddinger GR, Newman MC, Oris JT, Suter GW, Thompson T, Armitage TM, Meyer JL, Allen-King RM, Burton GA, Chapman PM, Conquest LL, Fernandez IJ, Landis WG, Master LL, Mitsch WJ, Mueller TC, Rabeni CF, Rodewald AD, Sanders JG, and van Heerden IL. 2008. Enhancing the ecological risk assessment process. Integrated Environmental Assessment and Management 4:306-313.

Davis RS. 2007. An ecological risk assessment for mosquito insecticides. Master's thesis. Montana State University.

Davis RS, Peterson RKD, and Macedo PA. 2007. An ecological risk assessment for insecticides used in adult mosquito management. Integrated Environmental Assessment and Management 3:373-382.

Devine OJ, and Qualters JR. 2008. Bayesian updating of model-based risk estimates using imperfect public health surveillance data. Human and Ecological Risk Assessment 14:696713.

Duprey Z, Rivers S, Luber G, Becker A, Blackmore C, Barr D, Weerasekera G, Kieszak S, Flanders WD, and Rubin C. 2008. Community aerial mosquito control and naled exposure. Journal of the American Mosquito Control Association 24:42-46.

Ellison AM. 1996. An introduction to Bayesian inference for ecological research and environmental decision-making. Ecological Applications 6:1036-1046.

Gargoum AS. 2001. Use of Bayesian dynamic models for updating estimates of contaminated material. Environmetrics 12:775-783.

Gelman A, Carlin JB, Stern HS, and Rubin DB. 2004. Bayesian data analysis. Boca Raton, FL: CRC Press. 
291 Gosselin N, Valcke M, Belleville D, and Samuel O. 2008. Human exposure to malathion during a 292 possible vector-control intervention against West Nile Virus. I: methodological framework 293 for exposure assessment. Human and Ecological Risk Assessment 14:1118-1137.

294 Grist EPM, O'Hagan A, Crane M, Sorokin N, Sims I, and Whitehouse P. 2005. Bayesian and 295 time-independent species sensitivity distributions for risk assessment of chemicals. 296 Environmental Science and Technology 40:395-401.

297 Hill RA. 1996. From science to decision-making: the applicability of Bayesian methods to risk 298 assessment. Human and Ecological Risk Assessment 2:636-642.

Hull RN, and Swanson S. 2006. Sequential analysis of lines of evidence - an advanced weight-of300 evidence approach for ecological risk assessment. Integrated Environmental Assessment and Management 2:302-311.

Karpati AM, Perrin MC, Matte T, Leighton J, Schwartz J, and Barr RG. 2004. Pesticide spraying 303 for West Nile virus control and emergency department asthma visits in New York City, 2000. Environmental Health Perspectives 112:1183-1187.

Kutz FW, and Strassman SC. 1977. Human urinary metabolites of organophosphate insecticides following mosquito adulticiding. Mosquito News 37:211-218.

Linkov I, Loney D, Cormier S, Satterstrom FK, and Bridges T. 2009. Weight-of-evidence evaluation in environmental assessment: Review of qualitative and quantitative approaches. Science of the Total Environment 407:5199-5205.

Macedo PA, Peterson RKD, and Davis RS. 2007. Risk assessments for exposure of deployed military personnel to insecticides and personal protective measures used for diseasevector management. Journal of Toxicology and Environmental Health, Part A 70:17581771. States. Clinical Infectious Diseases 33:1713-1719. 
316 McKone TE, Ryan PB, and Ozkaynak H. 2009. Exposure information in environmental health

317

318

319

320

321

322

323

324

325

326

327

328

329

330

331

332

333

334

335

336

337

338

research: current opportunities and future directions for particulate matter, ozone, and toxic air pollutants. Journal of Exposure Science and Environmental Epidemiology 19:3044.

Menzie C, Henning MH, Cura J, Finkelstein K, Gentile J, Maughan J, Mitchell D, Petron S, Potocki B, Svirsky S, and Tyler P. 1996. Report of the Massachusetts weight-of-evidence workgroup: a weight-of-evidence approach for evaluating ecological risks. Human and Ecological Risk Assessment 2:277-304.

Morris PA. 1977. Combining expert judgments: a Bayesian approach. Management Science 23:679-693.

NRC. 1994. Science and judgment in risk assessment. Washington D.C.: National Academy Press.

NRC. 1996. Understanding risk: informing decisions in a domcratic society. Washington, D.C.: National Academy Press.

NRC. 2009. Science and decisions: advancing risk assessment. Washington D.C.: National Academies Press.

NYCDOH. 2005. Adult mosquito control programs: environmental impact statement (EIS). New York, NY, USA: New York City Department of Health.

O'Sullivan BCY, Lafleur J, Fridal K, Hormozdi S, Schwartz S, Belt M, and Finkel M. 2005. The effect of pesticide spraying on the rate and severity of ED asthma. American Journal of Emergency Medicine 23:463-467.

Peterson RKD. 2006. Comparing ecological risks of pesticides: the utility of a risk quotient ranking approach across refinements of exposure. Pest Management Science 62:46-56. 
339 Peterson RKD, Macedo PA, and Davis RS. 2006. A human-health risk assessment for West Nile

340 virus and insecticides used in mosquito management. Environmental Health Perspectives

$341 \quad 114: 366-372$.

342 Reisen W, and Brault AC. 2007. West Nile virus in North America: perspectives on epidemiology 343 and intervention. Pest Management Science 63:641-646.

344 Roche JP. 2002. Print media coverage of risk-risk tradeoffs associated with West Nile encephalitis 345 and pesticide spraying. Journal of Urban Health: Bulletin of the New York Academy of $346 \quad$ Medicine 79:482-490.

347 Samet JM, Schnatter R, and Gibb H. 1998. Invited commentary: epidemiology and risk 348 assessment. American Journal of Epidemiology 148:929-936.

349 Sanchez-Bayo F, Baskaran S, and Kennedy IR. 2002. Ecological relative risk (EcoRR): another 350 approach for risk assessment of pesticides in agriculture. Agriculture Ecosystems \& $351 \quad$ Environment 91:37-57.

352 Schenker U, Scheringer M, Sohn MD, Maddalena RL, McKone TE, and Hungerbuhler K. 2009.

353 Using information on uncertainty to improve environmental fate modeling: a case study 354 on DDT. Environmental Science and Technology 43:128-134.

355 Schleier III JJ. 2008. Environmental concentrations, fate, and risk assessment of insecticides used 356 for adult mosquito management. Master's thesis. Montana State University.

357 Schleier III JJ, Davis RS, Barber LM, Macedo PA, and Peterson RKD. 2009a. A probabilistic risk 358 assessment for deployed military personnel after the implementation of the “Leishmaniasis Control Program” at Tallil Air Base, Iraq. Journal of Medical Entomology

361 Schleier III JJ, Davis RS, Shama LM, Macedo PA, and Peterson RKD. 2008a. Equine risk assessment for insecticides used in adult mosquito management. Human and Ecological Risk Assessment 14:392-407. 
364 Schleier III JJ, Macedo PA, Davis RS, Shama LM, and Peterson RKD. 2009b. A two-dimensional 365 probabilistic acute human-health risk assessment of insecticide exposure after adult 366 mosquito management. Stochastic Environmental Research and Risk Assessment 23:555367563.

368 Schleier III JJ, and Peterson RKD. 2010. Deposition and air concentrations of permethrin and 369 naled used for adult mosquito management. Archives of Environmental Contamination $370 \quad$ and Toxicology 58:105-111.

371 Schleier III JJ, Peterson RKD, Macedo PA, and Brown DA. 2008b. Environmental 372 concentrations, fate, and risk assessment of pyrethrins and piperonyl butoxide after aerial 373 ultralow-volume applications for adult mosquito management. Environmental Toxicology $374 \quad$ and Chemistry 27:1063-1068.

375 Smith EP, Lipkovich I, and Ye KY. 2002. Weight-of-evidence (WOE): Quantitative estimation of 376 probability of impairment for individual and multiple lines of evidence. Human and $377 \quad$ Ecological Risk Assessment 8:1585-1596.

378 Stauffer HB. 2008. Application of Bayesian statistical inference and decision theory to a 379 fundamental problem in natural resource science; the adaptive management of an $380 \quad$ endangered species. Natural Resource Modeling 21:264-284.

381 Suffolk County. 2006. Draft generic environmental impact statement. Suffolk County, NY:

382 Suffolk County Department of Public Works and Department of Health Services.

383 Suter II GW, and Cormier SM. 2011. Why and how to combine evidence in environmental 384 assessments: weighing evidence and building cases. Science of the Total Environment $385 \quad 409: 1406-1417$.

386 Sutton AJ, and Abrams KR. 2001. Bayesian methods in meta-analysis and evidence synthesis. 387 Statistical Methods in Medical Research 10:277-303. 
388 Taylor AC, Evans JS, and McKone TE. 1993. The value of animal test information in environmental control decisions. Risk Analysis 13:403-412.

390 Thier A. 2001. Balancing the risks: vector control and pesticide use in response to emerging illness. Journal of Urban Health: Bulletin of the New York Academy of Medicine 78:372381.

393 Tilghman A, Coquery M, Dulio V, and Garric J. 2009. Integrated chemical and biomonitoring strategies for risk assessment of emerging substances: report on the 4th thematic workshop of the EU Project NORMAN, Lyon, France, 17-18 March 2008. TrAC Trends in Analytical Chemistry 28:1-9.

397

398

399

400

401

402

403

404

405

406

407

408

409

410

411

412

USEPA. 1989. Risk assessment guidance for superfund. Volume I. Human health evaluation manual (Part A). Washington D.C.: U.S. Environmental Protection Agency.

USEPA. 2004. Risk assessment principles and practices: staff paper. Washington D.C.: U.S. Environmental Protection Agency.

USEPA. 2005a. Guidelines for carcinogen risk assessment. Washington D.C.: U.S. Environmental Protection Agency.

USEPA. 2005b. Memorandum from B. Davis, Health Effects Division, to C. Rodia, Special Review and Registration. Re: occupational and residential exposure assessment and recommendations for the reregistration elegibility decision (RED) for piperonyl butoxide. Washington D.C.: U.S. Environmental Protection Agency.

USEPA. 2005c. Memorandum from S.L. Kinard, Health Effects Division, to T. Moriarty, Special Review and Reregistration Division. Malathion: updated revised human health risk assessment for the reregistration eligibility decision document (RED). Washington D.C.: U.S. Environmental Protection Agency.

USEPA. 2005d. Memorandum from S.L. Kinard, Y. Yang and S. Ary, Health Effects Division, to J. Guerry, Special Review and Reregistration Division. Re: Permethrin. HED Chapter of 
413

414

415 USEPA. 2006a. Interim reregistration eligibility decision for naled, Case No. 0092. Washington

416

417

418

419

420

421

422

423

424

425

426

427

428

429

430 the Reregistration Eligibility Decision Document (RED). . Washington D.C.: U.S. Environmental Protection Agency. D.C.: U.S. Environmental Protection Agency. p 1-130.

USEPA. 2006b. Reregistration eligibility decision (RED) for permethrin. Washington D.C.: U.S. Environmental Protection Agency. p 1-95.

USEPA. 2006c. Reregistration eligibility decision for malathion. Washington D.C.: U.S. Environmental Protection Agency. p 1-101.

USEPA. 2006d. Technical overview of ecological risk assessment. Available at http://www.epa.gov/oppefed1/ecorisk_ders/toera_risk.htm (accessed 1 November 2006).

Valcke M, Gosselin N, and Belleville D. 2008. Human exposure to malathion during a possible vector-control intervention against West Nile Virus. II: evaluation of the toxicological risks using a probabilistic approach. Human and Ecological Risk Assessment 14:11381158.

Weed DL. 2005. Weight of evidence: a review of concept and methods. Risk Analysis 25:15451557.

Wheeler MW, and Bailer AJ. 2009. Benchmark dose estimation incorporating multiple data sources. Risk Analysis 29:249-256.

431 Zadeh L. 1965. Fuzzy sets. Information and Control 8:338-353. 
432 Equation 2 as it should appear in the published paper:

$$
\begin{gathered}
y-\theta \dot{i}^{2} \\
\frac{-1}{2 \sigma^{2}} \dot{ } \\
p(y \mid \theta)=\frac{1}{\sqrt{2 \pi \sigma}} \exp \dot{ }
\end{gathered}
$$




\section{Table $\mathbf{1}$ (on next page)}

Risk quotient estimates for each study 
Table 1. Risk quotient estimates for each study

\begin{tabular}{|c|c|c|}
\hline & Malathion & Permethrin \\
\hline Karpati et al. $(\underline{2004})^{\mathrm{c}}$ & $\mathrm{NA}^{\mathrm{a}}$ & $0.99^{\mathrm{b}}$ \\
\hline USEPA $(\underline{2005 \mathrm{c}}, \underline{\mathrm{d}})^{\mathrm{d}}$ & 0.018 & 0.025 \\
\hline Currier et al. $(\underline{2005})^{\mathrm{e}}$ & $\mathrm{NA}^{\mathrm{a}}$ & $0.99^{\mathrm{b}}$ \\
\hline O'Sullivan et al. $(\underline{2005})^{\mathrm{c}}$ & $0.99^{\mathrm{b}}$ & $\mathrm{NA}^{\mathrm{a}}$ \\
\hline Peterson et al. $(\underline{2006})^{d}$ & 0.0076 & 0.0021 \\
\hline Suffolk County $(\underline{2006})^{\mathrm{d}}$ & 0.015 & 0.013 \\
\hline Macedo et al. $(\underline{2007})^{d}$ & $\mathrm{NA}^{\mathrm{a}}$ & 0.023 \\
\hline Valcke et al. $(\underline{2008})^{d}$ & 0.64 & $\mathrm{NA}^{\mathrm{a}}$ \\
\hline Schleier III $(\underline{2008})^{d}$ & $\mathrm{NA}^{\mathrm{a}}$ & 0.00025 \\
\hline Schleier III et al. $(\underline{2009 a})^{d}$ & 0.02 & $\mathrm{NA}^{\mathrm{a}}$ \\
\hline Schleier III et al. $(\underline{2009 b})^{d}$ & 0.0017 & 0.000068 \\
\hline
\end{tabular}

${ }^{a}$ Not applicable because the chemical was not assessed

${ }^{\mathrm{b}} \mathrm{A}$ risk quotient of 0.99 was used because it provides a conservative estimate of the risk for biomonitoring and epidemiology studies and due to a lack of knowledge about the true value, which must be below 1 if no effect is seen.

${ }^{\mathrm{c}}$ Epidemiological study

${ }^{\mathrm{d}}$ Risk assessment

${ }^{\mathrm{e}}$ Biomonitoring study 
1

Figure 1: Posterior probability distributions for malathion with all available studies and all studies excluding epidemiological and biomonitoring.

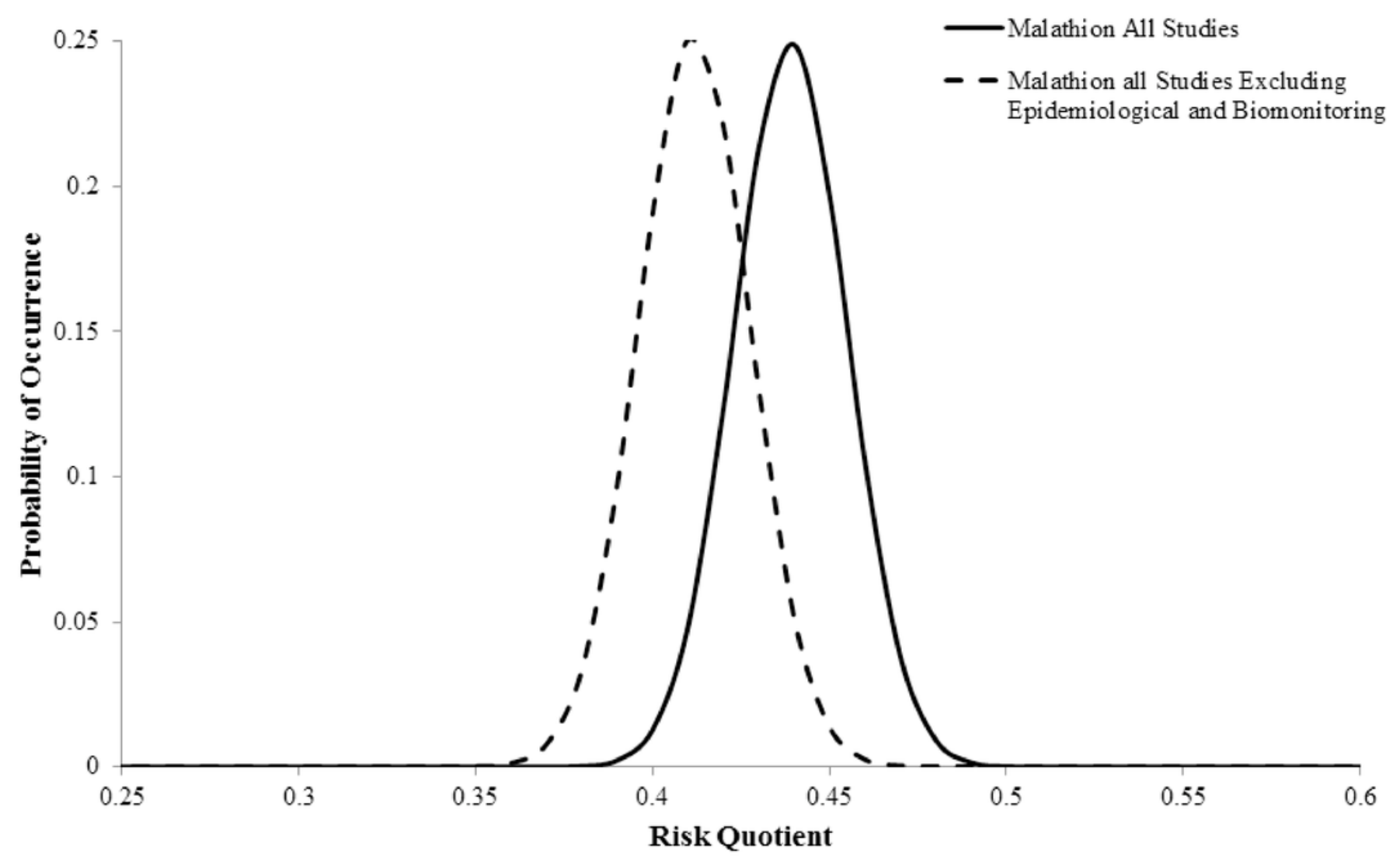


2

Figure 2: Posterior probability distributions for permethrin with all available studies and all studies excluding epidemiological and biomonitoring.

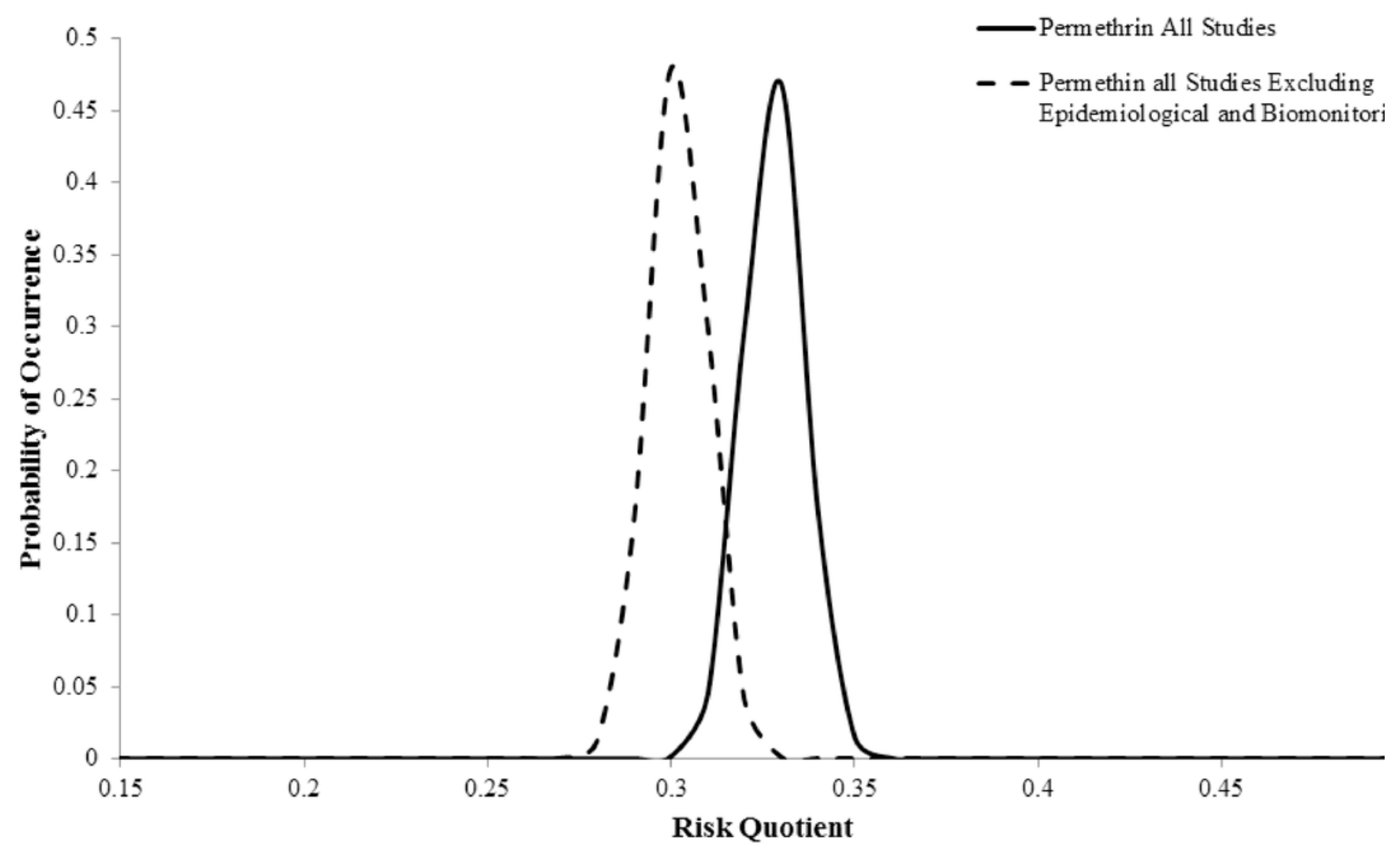

